\title{
Alteração dos metabólitos secundários em plantas de Hypericum perforatum L. (Hypericaceae) submetidas à secagem e ao congelamento
}

\author{
Ana Carolina Boeno Diniz ${ }^{1}$, Leandro Vieira Astarita ${ }^{2}$ e Eliane Romanato Santarém²,3
}

\author{
Recebido em 23/02/2006. Aceito em 27/10/2006
}

\begin{abstract}
RESUMO - (Alteração dos metabólitos secundários em plantas de Hypericum perforatum L. (Hypericaceae) submetidas à secagem e ao congelamento). Nos últimos anos, o interesse por Hypericum perforatum tem aumentado devido à sua ação antiviral, antidepressiva e moduladora de apoptose em células neoplásicas. O preparo do material vegetal, após ser colhido, envolve freqüentemente a dessecação ou o congelamento e posterior armazenamento, processos que podem alterar o perfil dos metabólitos secundários. Neste sentido, este trabalho avaliou o efeito da secagem, do congelamento e da estocagem sob baixas temperaturas na quantidade de flavonóides e de hipericina nas partes vegetativas de plantas de hipérico. Ramos de hipérico foram submetidos à secagem a $25,30,50$ e $70{ }^{\circ} \mathrm{C}$, congelados em nitrogênio líquido ou congelados e armazenados a $-20{ }^{\circ} \mathrm{C}$ por 10,20 e 30 dias. A quantificação dos flavonóides e de hipericina foi realizada por cromatografia líquida de alta eficiência (CLAE). Os teores de flavonóides e de hipericina foram afetados pela temperatura de secagem. Secagem a $25{ }^{\circ} \mathrm{C}$ causou redução nos teores de grande parte dos metabólitos analisados, enquanto a $50{ }^{\circ} \mathrm{C}$, os teores de rutina livre e glicosilada, de quercetina e quercitrina glicosiladas e de hipericina foram preservados. Apigenina livre e canferol não sofreram reduções significativas nas suas concentrações, independente das temperaturas de secagem. O tratamento de congelamento e imediata análise das amostras não alterou o perfil dos flavonóides, mas causou redução do nível de hipericina nas plantas de hipérico.
\end{abstract}

Palavras-chave: flavonóides, hipericina, metabolismo secundário, plantas medicinais, produtos naturais

\begin{abstract}
Secondary metabolite content in Hypericum perforatum L. (Hypericaceae) plants submitted to drying and freezing). In recent years, interest in Hypericum perforatum has increased due to its antiviral, antidepressive and apoptosis-inducing properties. Plant material preparation after harvesting often includes dehydration or freezing and further storage, and these procedures can lead to variations in the secondary metabolite profile. In this study the effects of drying, freezing and storage at $-20{ }^{\circ} \mathrm{C}$ on flavonoid and hypericin content in $H$. perforatum were evaluated. Leaves and stems of $H$. perforatum were dried at $25,30,50$ and $70{ }^{\circ} \mathrm{C}$, frozen in liquid nitrogen or frozen and then stored at $-20^{\circ} \mathrm{C}$ for 10,20 and 30 days. Flavonoid and hypericin quantification was performed by High Performance Liquid Chromatography (HPLC). Levels of both flavonoids and hypericin were affected by drying temperature. Drying at $25^{\circ} \mathrm{C}$ resulted in lower levels of most of the metabolites analyzed while at $50{ }^{\circ} \mathrm{C}$, levels of free and conjugated rutin, conjugated quercetin and quercitrin as well as hypericin content were maintained when compared to fresh samples. Free apigenin and kaempferol did not show any significant variation, regardless of drying temperature. Freezing did not affect the profile of flavonoids, but it led to significant reduction in hypericin content.
\end{abstract}

Key words: flavonoids, hypericin, secondary metabolism, medicinal plants, natural products

\section{Introdução}

A presença de moléculas bioativas em plantas de interesse medicinal tem sido amplamente estudada nos últimos anos, devido à crescente popularidade dos medicamentos fitoterápicos. Entre as espécies de grande interesse farmacêutico, encontra-se Hypericum perforatum L., uma planta da família Hypericaceae (APG 2003), comumente conhecida como hipérico. Esta planta herbácea e perene, naturalmente encontrada em regiões temperadas da
Europa, da Ásia e da África, tem sido tradicionalmente usada na medicina popular por sua ação cicatrizante, diurética, bactericida, analgésica e antiinflamatória (Alan \& Muller 1998). Mais recentemente, os extratos de $H$. perforatum têm sido utilizados nos tratamentos de depressões leves e moderadas e nos distúrbios do sono (Vitiello 1999).

Os principais grupos de constituintes bioativos relacionados às propriedades medicinais de Hypericum perforatum incluem as naftodiantronas (hipericina e pseudohipericina), os flavonóides (rutina, quercetina,

\footnotetext{
1 Universidade de Cruz Alta, Laboratório de Cultura de Tecidos Vegetais, C. Postal 858, 95810-025 Cruz Alta, RS, Brasil

2 Pontifícia Universidade Católica do Rio Grande do Sul, Faculdade de Biociências, Laboratório de Biotecnologia Vegetal, Av. Ipiranga 6681, Pd.12A, 90619-900 Porto Alegre, RS, Brasil

3 Autor para correspondência: esantarem@pucrs.br
} 
quercitrina, isoquercitrina e hiperosídeo) e os floroglucinóis (hiperforina e adhiperforina) (Bombardelli \& Morazzoni 1995). Os flavonóides representam 2 a $4 \%$ do extrato das plantas de hipérico e são moléculas com reconhecida atividade antioxidante (Vitiello 1999; Bilia et al. 2002). Entre as naftodiantronas, a hipericina parece ser um importante produto do metabolismo secundário do gênero Hypericum, sendo encontrada em 27 das 36 espécies estudadas (Kitanov 2001). Por suas propriedades fotodinâmicas, a hipericina e a pseudohipericina apresentaram efeito citotóxico e indutor de apoptose em linhagens de células neoplásicas, tendo sido recentemente sugeridas como agentes no tratamento do câncer (Agostinis et al. 2002; Schempp et al. 2002).

Entre as propriedades medicinais relatadas para os extratos de hipérico, o efeito antidepressivo é o que tem despertado maior interesse e vários estudos clínicos demonstraram que o hipérico é tão efetivo quanto os antidepressivos sintéticos (Woelk 2000; Bilia et al. 2002). Inicialmente, acreditava-se que a hipericina fosse a molécula responsável por esta propriedade (Thiede \& Walper 1994). No entanto, estudos recentes têm demonstrado que a hiperforina (Laakman et al. 1998) e alguns flavonóides, como a rutina, podem também estar atuando na ação antidepressiva (Butterweck et al. 2000; Nöldner \& Schötz 2002). Como a eficácia dos extratos de hipérico não está diretamente relacionada a apenas um constituinte, a qualidade fitoquímica do material bruto deve ser avaliada quanto à presença e à concentração de compostos previamente determinados como benéficos (Gray et al. 2003). Além disso, a quantidade de moléculas bioativas nas plantas de hipérico pode ser alterada por vários fatores, como época do ano (Southwell \& Bourke 2001), partes da planta (Constantine \& Karchesy 1998), variações genotípicas e ambientais (Büter et al. 1998) e níveis de ploidia (Kosuth et al. 2003). As técnicas utilizadas para coleta, secagem e armazenamento do material vegetal também podem alterar os teores dos compostos bioativos (Martins et al. 1998; Böttcher et al. 2003). A temperatura utilizada no processo de secagem do material vegetal pode agir alterando os teores dos metabólitos de interesse (Calixto 2000), sendo preferível utilizar altas temperaturas de secagem a fim de inibir a ação de enzimas e a atividade microbiana (Ming 1994). Tanto o processo de secagem quanto o de armazenamento podem promover rearranjos, oxidações e reduções das moléculas bioativas, levando à perda de qualidade do produto fitoterápico. A secagem do material vegetal em temperaturas próximas a $30^{\circ} \mathrm{C}$ levou à redução da concentração de cumarina em Mikania glomerata Spreng., mas preservou o teor de hipericina em Hypericum perforatum (Pereira et al. 2000; Böttcher et al. 2003), indicando que o método utilizado para o beneficiamento pode depender da característica química das moléculas de interesse.

Nesse sentido, este trabalho teve por objetivo quantificar os flavonóides e a hipericina em plantas cultivadas de Hypericum perforatum, bem como avaliar o efeito de diferentes temperaturas de secagem, do congelamento e do período de estocagem das amostras sob baixas temperaturas na concentração destes compostos nas partes aéreas das plantas.

\section{Material e métodos}

O cultivo das plantas de Hypericum perforatum foi conduzido em Latossolo Vermelho Distrófico, de textura argilosa, no município de Cruz Alta, RS, Brasil (2838'19'S; 53³6'23'”), com tipo climático Cfa1 (classificação climática de Koeppen; Brasil 1978). Os ramos vegetativos das plantas (aproximadamente 15 $\mathrm{cm}$ de comprimento) foram obtidos em uma única coleta (26/novembro/2001), sendo aleatoriamente acondicionados em embalagens de papel opaco e imediatamente submetidos aos diferentes tratamentos de secagem. As temperaturas avaliadas foram 25, 30 , 50 e $70{ }^{\circ} \mathrm{C}$. Com exceção da temperatura de $25^{\circ} \mathrm{C}$, as amostras foram mantidas em estufa até atingirem massa constante (de três a cinco dias). Após a secagem, o material vegetal foi separado em amostras de $1 \mathrm{~g}$, consistindo de quatro repetições por tratamento e estocado em temperatura ambiente para posterior análise. O controle consistiu de amostra de material fresco (quatro repetições de $1 \mathrm{~g}$ cada). Para comparar o conteúdo de compostos secundários das amostras desidratadas com as amostras de material fresco, foi aplicado um fator de conversão de massa fresca (MF) em massa seca (MS), com base na expressão MS/ MF. Os valores utilizados para o cálculo do fator de conversão representam a média de 10 amostras de $1 \mathrm{~g}$ de massa fresca, submetidas à secagem. As concentrações de flavonóides e hipericina obtidas nas amostras de material fresco foram divididas pelo fator de conversão obtido $(0,255)$ para comparação com os tratamentos de secagem.

Para avaliar o efeito do congelamento do material vegetal na quantidade dos compostos secundários, partes aéreas de hipérico em estágio vegetativo foram 
coletadas sob as mesmas condições descritas anteriormente e congeladas em $\mathrm{N}_{2}$ líquido. $\mathrm{O}$ período de armazenamento das amostras sob baixas temperaturas $\left(-20{ }^{\circ} \mathrm{C}\right)$ também foi analisado e a extração da hipericina e dos flavonóides foi realizada 10,20 e 30 dias após o congelamento. O material fresco foi utilizado como controle absoluto e o material congelado a $-20^{\circ} \mathrm{C}$ e imediatamente submetido à extração e análise, como controle relativo. Cada tratamento consistiu de quatro repetições de $1 \mathrm{~g}$ de massa fresca, separadas antes do congelamento.

Os compostos do metabolismo secundário analisados nas amostras de hipérico foram os flavonóides rutina, quercetina, quercitrina, apigenina e canferol e a naftodiantrona hipericina. Para análise dos flavonóides, as amostras foram homogeneizadas manualmente em $10 \mathrm{~mL}$ de solução de metanol e água $(80: 20 \mathrm{v} / \mathrm{v})$. Do extrato bruto, $5 \mathrm{~mL}$ foram filtrados através de membrana de $0,45 \mu \mathrm{m}$ e, posteriormente, passados em colunas $\mathrm{C}_{18}$ (Sep-Pack ${ }^{\mathrm{TM}}$, Waters Co.). A quantificação dos flavonóides glicosilados foi realizada a partir da hidrólise ácida das amostras em solução de $\mathrm{HCl}(1 \mathrm{M})$, a $50{ }^{\circ} \mathrm{C}$, por 24 h (modificado de Crozier et al. 1997). Para a quantificação da hipericina, o material vegetal foi macerado em $10 \mathrm{~mL}$ de metanol 100\%, segundo Santarém \& Astarita (2003). Todos os extratos foram armazenados a $-20{ }^{\circ} \mathrm{C}$ até a análise cromatográfica.

A quantificação de flavonóides e hipericina foi realizada utilizando-se cromatografia líquida de alta eficiência (CLAE), no sistema Gilson (Gilson Medical Eletronics, França), modelo 321, coluna fase reversa MetaSil ODS ( $5 \mu \mathrm{m} ; 150 \times 4,6 \mathrm{~mm})$, utilizando detector UV/VIS, ajustado em $258 \mathrm{~nm}$ e em $590 \mathrm{~nm}$, para flavonóides e hipericina, respectivamente. O equipamento foi operado à temperatura ambiente $(25 \pm$ $2{ }^{\circ} \mathrm{C}$ ) e os dados cromatográficos foram obtidos e processados pelo sistema Unipoint ${ }^{\circledR}$. Para análise dos flavonóides, os solventes utilizados foram $2 \%$ de ácido fosfórico em água (v/v) (eluente A) e acetonitrila (eluente B). O gradiente da fase móvel consistiu de 20 a $50 \%$ do eluente B de 0 a $25 \mathrm{~min}, 50$ a $100 \%$ de B de 25 a 26 min, e $100 \%$ de B até 29 min. Para a quantificação da hipericina, o gradiente linear foi estabelecido entre $2 \%$ de ácido fosfórico em água (v/v) e acetonitrila: metanol (70:30 v/v), conforme descrito em Santarém \& Astarita (2003). Em ambas as análises, o fluxo foi mantido em $1 \mathrm{~mL} \mathrm{~min}{ }^{-1}$. A identificação e quantificação dos flavonóides e da hipericina foram realizadas a partir de curvas de calibração, considerando-se os tempos de retenção e as áreas dos picos dos padrões adquiridos comercialmente.

As concentrações de flavonóides e hipericina obtidas pela análise cromatográfica foram submetidas à transformação raiz quadrada $(x+1)$ e posteriormente aos testes de normalidade (Shapiro-Wilk) e de homogeneidade (Bartlett). Comparações múltiplas foram feitas pela análise da variância e comparações binárias pelo teste de Tukey, ambos a 0,05 de significância, com auxílio do programa estatístico SPSS v.11.

\section{Resultados}

Análise do material fresco - Entre os flavonóides livres quantificados no material fresco de hipérico, a rutina foi encontrada em quantidades mais elevadas (96 $\mathrm{mg} \mathrm{g}^{-1} \mathrm{MS}$ ), seguida por quercitrina, com concentração média de 5,4 $\mathrm{mg} \mathrm{g}^{-1} \mathrm{MS}$ (Fig. 1A, B). Apigenina e canferol estavam presentes em baixas concentrações $\left(0,04\right.$ e $0,08 \mathrm{mg} \mathrm{g}^{-1} \mathrm{MS}$, respectivamente) (Fig. 1C, D). No entanto, a hidrólise ácida dos extratos de material fresco demonstrou que a apigenina $\left(0,43 \mathrm{mg} \mathrm{g}^{-1} \mathrm{MS}\right)$ e o canferol $\left(0,35 \mathrm{mg} \mathrm{g}^{-1} \mathrm{MS}\right)$ foram detectados em concentrações 10,7 e 4,4 vezes maiores, respectivamente, do que seus correspondentes agliconas (Fig. 1C, D). A quercetina somente foi detectada nas amostras na sua forma glicosilada (20,8 $\mathrm{mg} \mathrm{g}^{-1} \mathrm{MS}$; Fig. 1E). A análise das partes aéreas frescas de $H$. perforatum demonstrou a presença de $3,83 \mathrm{mg} \mathrm{g}^{-1}$ MS de hipericina (Fig. 1F).

Efeito das temperaturas de secagem - Quando comparado ao material fresco, o processo de secagem das amostras reduziu significativamente os teores de rutina e quercitrina livres (Fig. 1A, B), com exceção da temperatura de $50{ }^{\circ} \mathrm{C}$, que manteve a concentração de rutina semelhante àquela encontrada no material fresco (Fig. 1A). A apigenina e o canferol livres não sofreram redução significativa das suas concentrações nas diferentes temperaturas testadas, apesar da baixa quantidade encontrada nas plantas de hipérico (Fig. 1C, D).

A temperatura de secagem também afetou o perfil de flavonóides do extrato hidrolisado. A variação mais drástica ocorreu quando a secagem foi realizada a $25^{\circ} \mathrm{C}$, havendo redução dos teores de grande parte dos flavonóides analisados (Fig. 1A-E). A concentração de apigenina glicosilada foi reduzida em todas as temperaturas testadas (Fig. 1C), enquanto que, a temperatura de $50{ }^{\circ} \mathrm{C}$ pareceu preservar os teores de rutina, quercitrina e quercetina glicosiladas (Fig. 1A, B, E). A concentração de canferol glicosilado, a 
exemplo do observado com o canferol livre, não apresentou variação significativa entre os tratamentos (Fig. 1D). A concentração de hipericina também não foi afetada a $50{ }^{\circ} \mathrm{C}$, quando comparada ao teor observado no material fresco (Fig. 1F).

Efeito do congelamento e do período de estocagem Os resultados obtidos com o congelamento das amostras em $\mathrm{N}_{2}$ líquido e a imediata análise cromatográfica mostraram que não há alteração no perfil de flavonóides livres e glicosilados, quando comparado ao material fresco (Fig. 2A-E), mas houve redução significativa no teor de hipericina (Fig. 2F). No entanto, o período de estocagem das amostras sob baixas temperaturas reduziu significativamente os teores da maioria dos flavonóides livres e glicosilados e da hipericina (Fig. 2A-F).

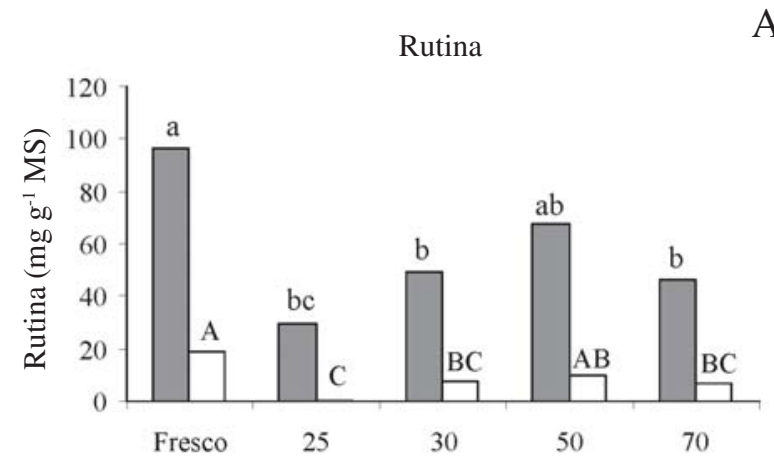

A
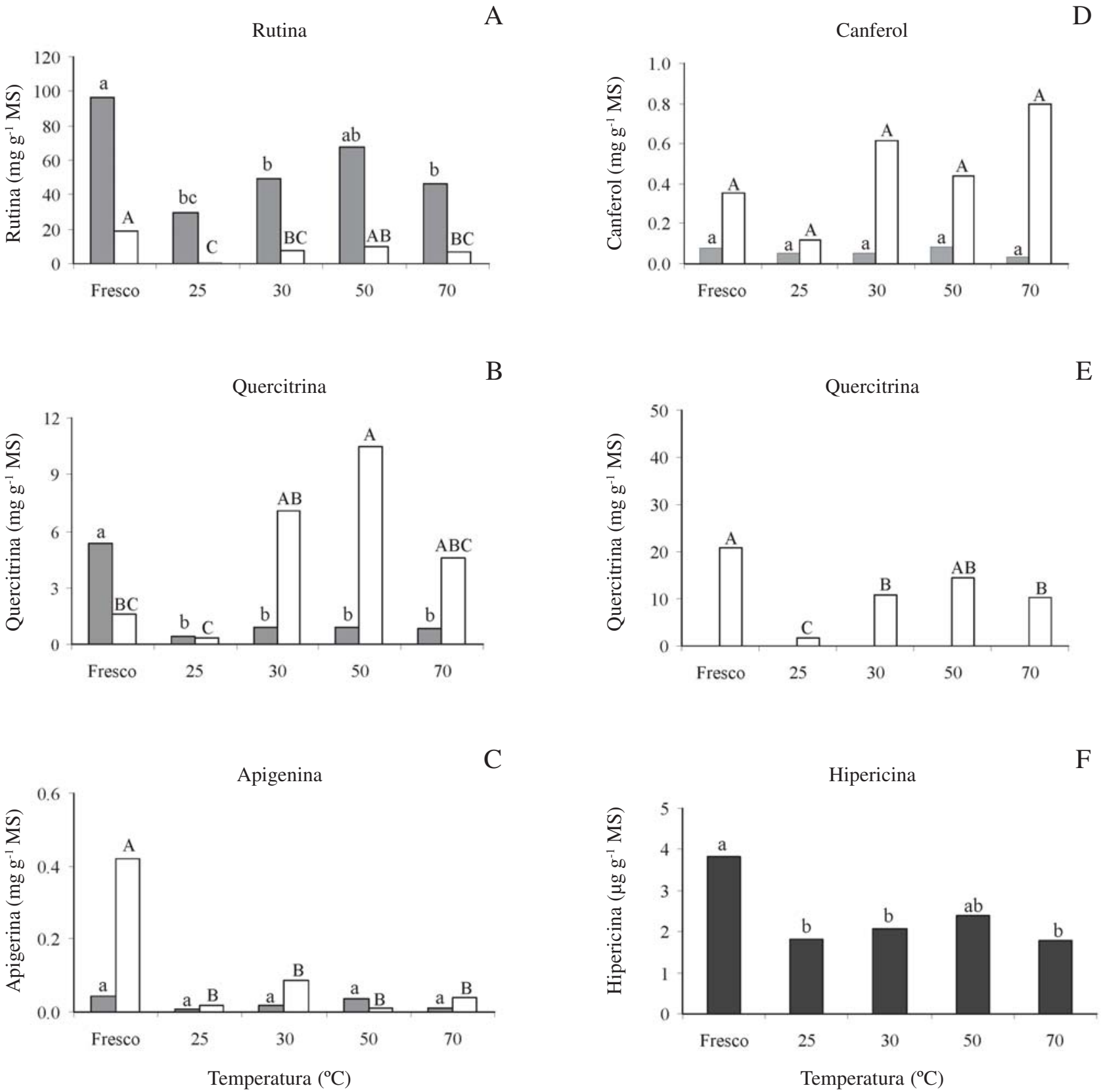

Figura 1. Efeito da temperatura de secagem de ramos vegetativos de Hypericum perforatum L. nos níveis de flavonóides livres e glicosilados e de hipericina. As concentrações determinadas nas amostras de material fresco foram transformadas para massa seca, utilizando-se o fator de conversão 0,255. Letras iguais, minúsculas nas barras preenchidas e maiúsculas nas barras claras, indicam não haver diferença significativa pelo teste de Tukey $(P>0,05)$. ( $\square=$ flavonóides livres; $\square=$ flavonóides glicosilados; $\square=$ hipericina $)$. 


\section{Discussão}

Os flavonóides são referidos como moléculas abundantes em Hypericum perforatum, principalmente os flavonóis, as flavonas, as catequinas e as flavononas (Bilia et al. 2002). Vários estudos de quantificação de flavonóides em plantas desta espécie têm sugerido que as quantidades totais de rutina, quercetina e quercitrina podem variar de 2 a $4 \%$ da matéria seca (Wheatley 1998). Nos ramos vegetativos de hipérico cultivados em Cruz Alta, a rutina e a quercitrina foram os flavonóides livres encontrados em maior concentração, enquanto apigenina e canferol livres foram detectados em concentrações menores do que $0,1 \mathrm{mg} \mathrm{g}^{-1} \mathrm{MS}$. Estudo com plantas de hipérico em diferentes fases do desenvolvimento mostrou que

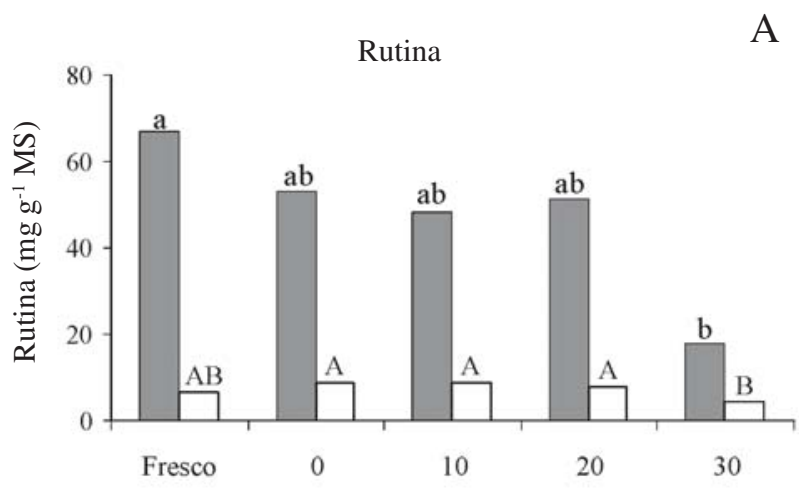

Rutina

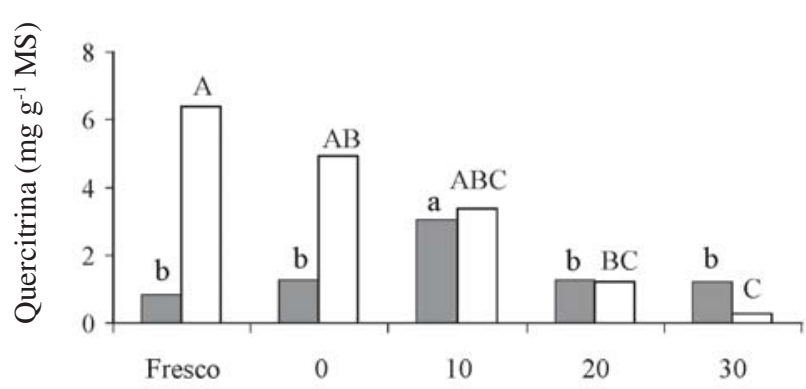

Rutina

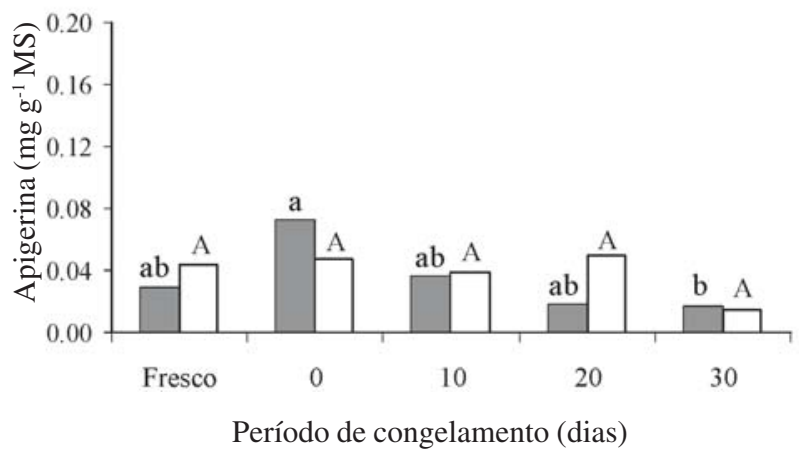

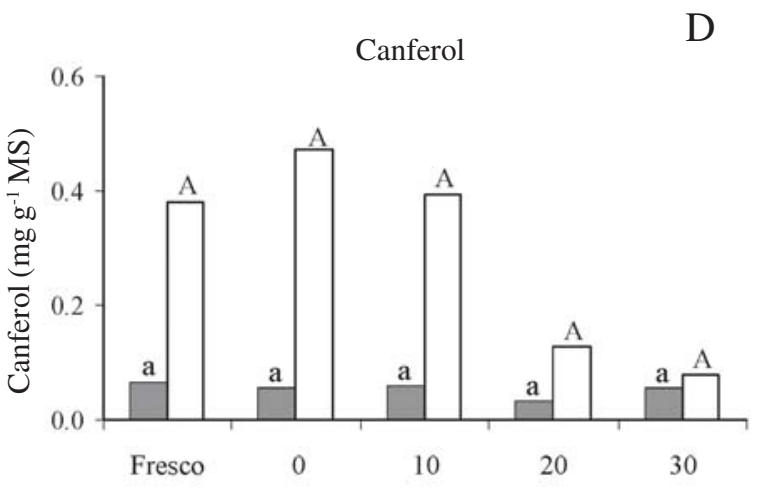

Canferol

$\mathrm{E}$

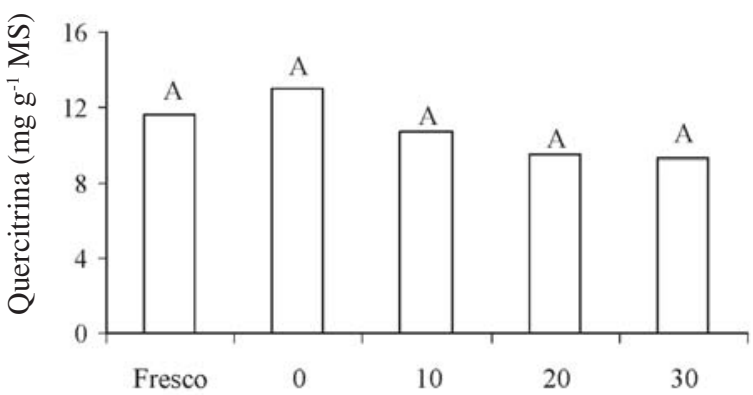

F

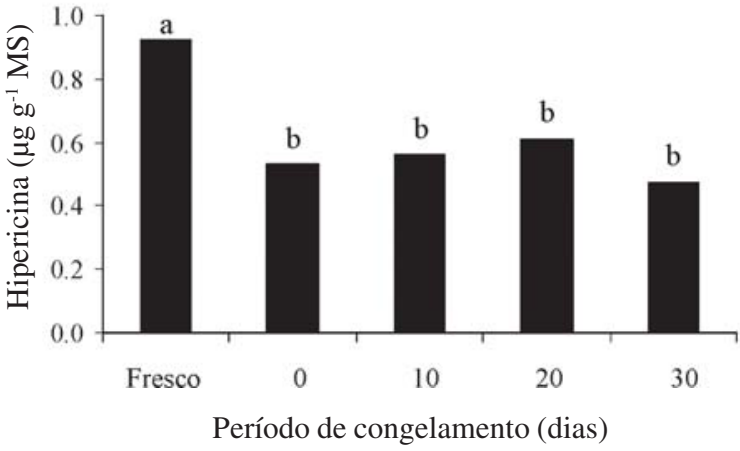

Figura 2. Efeito do congelamento e do período de estocagem a baixas temperaturas de ramos vegetativos de Hypericum perforatum L. nos níveis de flavonóides livres e glicosilados e de hipericina. Período de congelamento representado por 0 dia corresponde ao material congelado e analisado imediatamente. Letras iguais, minúsculas nas barras preenchidas e maiúsculas nas barras claras, indicam não haver diferença significativa pelo teste de Tukey $(P>0,05)$. ( $\square=$ flavonóides livres; $\square=$ flavonóides glicosilados; $\square=$ hipericina). 
a rutina foi o flavonóide encontrado em maior quantidade nas folhas, enquanto a quercetina estava presente em concentrações mais elevadas nas flores (Kazlauskas \& Bagdonaitë 2004). Por outro lado, na análise de flores e frutos de $H$. perforatum coletados em diferentes regiões da Itália, a rutina foi encontrada em maior quantidade do que a quercetina e seus derivados (Pietta et al. 2001). As variações observadas no perfil dos flavonóides analisados podem ser conseqüência das diferenças nas condições ambientais, da variabilidade genética ou das partes da planta utilizadas para a análise, fatores que comprovadamente alteram a produção dos metabólitos secundários (Büter et al. 1998; Constantine \& Karchesy 1998).

A análise dos extratos hidrolisados revelou que a apigenina, o canferol e a quercetina encontravam-se principalmente na forma conjugada. Resultados semelhantes foram obtidos na quantificação de flavonóis em extratos hidrolisados de hipérico, onde a quercetina foi o flavonol mais abundante (Stefova et al. 2001). Škerget et al. (2005) relataram que, entre os flavonóides analisados nas plantas de hipérico, a quercetina e o canferol encontravam-se glicosilados, nas concentrações de 1,4 e $0,012 \mathrm{mg} \mathrm{g}^{-1} \mathrm{MF}$, respectivamente. Nas plantas superiores, grande parte dos flavonóides presentes nos tecidos vegetais encontra-se conjugada a moléculas de carboidratos (Crozier et al. 1997; Škerget et al. 2005). Segundo Harborne \& Williams (2000), o canferol e a quercetina são os flavonóis mais freqüentemente encontrados na forma conjugada a carboidratos, representando uma estratégia de adaptação e sobrevivência das plantas relacionada à proteção contra a radiação UV-B.

Entre os compostos do metabolismo secundário analisados neste estudo, a hipericina foi a molécula encontrada em menor concentração $\left(3,83 \mu \mathrm{g} \mathrm{g}^{-1} \mathrm{MS}\right.$, representando 0,00038\%). Embora vários estudos tenham determinado a presença deste composto em plantas de hipérico, as concentrações variam amplamente de acordo com a origem do material. Por exemplo, plantas coletadas no Canadá apresentaram 0,01 a $0,06 \%$ de hipericina, enquanto nos Estados Unidos a variação foi de 0,11 a $0,38 \%$ (Jensen et al. 1995; Constantine \& Karchesy 1998). Além de tal variação, foi relatado que as partes aéreas vegetativas de hipérico apresentam teores de hipericina menores do que o das flores (Kazlauskas \& Bagdonaitë 2004). Devido à dificuldade de florescimento de plantas de hipérico na região sul do Brasil, os resultados obtidos neste trabalho indicam que o cultivo comercial desta espécie para obtenção de hipericina pode não ser viável nesta região.

Grande parte das plantas medicinais utilizadas para a produção de medicamentos fitoterápicos é comercializada na forma dessecada, mas o processo de secagem pode alterar o perfil dos metabólitos secundários deste material (Calixto 2000). A temperatura utilizada durante o beneficiamento da matéria-prima parece ser o fator determinante para a manutenção das propriedades terapêuticas das plantas de hipérico (Constantine \& Karchesy 1998). Isto foi confirmado pelos resultados obtidos, uma vez que as amostras dessecadas a $25^{\circ} \mathrm{C}$ tiveram os teores de rutina e quercitrina livres, de rutina, apigenina e quercetina glicosiladas e de hipericina alterados de modo significativo. O material vegetal, quando colhido, apresenta elevado teor de umidade, o que favorece as oxidações, reduções, rearranjos moleculares, hidrólises e remoção ou adição de radicais, resultando em alterações nos princípios ativos (Martins et al. 1998). Neste sentido, a utilização de temperaturas entre 35 e $45^{\circ} \mathrm{C}$ tem sido relatada como ideal para a desidratação de plantas medicinais (Martins et al. 1998). Böttcher et al. (2003) relataram a redução de $20 \%$ nos níveis de hipericina em ramos e flores de Hypericum perforatum estocados a 10 e $20{ }^{\circ} \mathrm{C}$ por até 80 horas. Segundo estes autores, a estocagem do material vegetal a $30^{\circ} \mathrm{C}$ não reduziu o conteúdo de hipericina nas plantas analisadas, embora os autores tenham relatado que os resultados variaram em relação ao período de coleta e ao estágio de desenvolvimento das plantas. Pereira et al. (2000) observaram que o conteúdo de cumarina de folhas de Mikania glomerata foi reduzido quando as folhas foram submetidas à secagem a $35^{\circ} \mathrm{C}$, enquanto a $50^{\circ} \mathrm{C}$, a perda foi menor. De modo geral, temperaturas mais elevadas permitem a secagem mais rápida do material vegetal, inibindo mais rapidamente a ação das enzimas ou a atividade microbiana, fatores que podem levar a alterações no perfil dos constituintes químicos da espécie (Ming 1994). Por outro lado, temperaturas acima de $60^{\circ} \mathrm{C}$ podem modificar o conteúdo metabólico das células (Martins et al. 1998). Os resultados das análises dos ramos de hipérico corroboram estas observações, pois o material vegetal submetido à secagem a $50{ }^{\circ} \mathrm{C}$ permitiu a manutenção dos níveis de rutina livre, de quercetina e quercitrina glicosiladas e de hipericina, quando comparadas ao material fresco. A temperatura de $70{ }^{\circ} \mathrm{C}$ causou diminuição nos níveis da maioria dos compostos analisados.

Nos estudos de compostos secundários produzidos pelas plantas, o material vegetal é freqüentemente 
congelado e armazenado sob baixas temperaturas, sendo posteriormente submetido aos processos de extração e análise dos metabólitos. Os resultados obtidos indicam que, para a análise do conteúdo de flavonóides, submeter as amostras à extração, imediatamente após o congelamento, representa a melhor estratégia para minimizar as perdas destas moléculas, pois o armazenamento das amostras sob $-20{ }^{\circ} \mathrm{C}$ por 30 dias pode alterar os níveis de alguns flavonóides. A estocagem das amostras sob baixas temperaturas pode ser viável quando o flavonóide alvo do estudo for quercetina ou canferol, moléculas que não tiveram seus conteúdos alterados por este processo de armazenamento. Por outro lado, tanto o congelamento quanto a estocagem a $-20^{\circ} \mathrm{C}$ causaram redução significativa nos níveis de hipericina.

Os resultados apresentados neste trabalho indicam que, dependendo da temperatura utilizada, o processo de secagem de amostras de Hypericum perforatum pode alterar as concentrações dos flavonóides livres e glicosilados e de hipericina. O mesmo efeito foi observado quando o material vegetal foi congelado e armazenado sob baixas temperaturas. A redução na concentração de hipericina devido à secagem ou ao congelamento e armazenamento a $-20{ }^{\circ} \mathrm{C}$ representa uma limitação para o preparo de medicamentos fitoterápicos a partir de $H$. perforatum, porque esta molécula é geralmente utilizada para a padronização dos extratos desta espécie.

\section{Referências bibliográficas}

Agostinis, P.; Vantieghem, A.; Merlevede, W. \& Witte, P.A.M. 2002. Hypericin in cancer treatments: more light on the way. The International Journal of Biochemistry \& Cell Biology 34(3): 221-241.

Alan, L. \& Muller, N.D. 1998. St. John's Wort (Hypericum perforatum): clinical effects on depression and other conditions. Alternative Medicine Review 3(1): 18-26.

APG. 2003. An update of the angiosperm phylogeny group. Classification for the orders and families of flowering plants: APG II. Botanical Journal of the Linnean Society 141(4): 399-436.

Bilia, A.R.; Gallori, S. \& Vincieri, F.F. 2002. St. John's wort and depression. Efficacy, safety and tolerability - an update. Life Sciences 70(26): 3077-3096.

Bombardelli, E. \& Morazzoni, P. 1995. Hypericum perforatum. Fitoterapia 66(1): 43-60.

Böttcher, H.; Günther, I. \& Kabelitz, L. 2003. Physiological postharvest responses of common Saint-John's wort herbs (Hypericum perforatum L.). Postharvest Biology and Technology 29(3): 342-350.
Brasil, 1978. Aptidão Agrícola das Terras. Estudos básicos para o planejamento agrícola. Brasília, DF, Ministério da Agricultura -SUPLAN.

Büter, B.; Orlacchio, C.; Soldati, A. \& Berger, K. 1998. Significance of genetic and environmental aspects in the field cultivation of Hypericum perforatum. Planta Medica 64(5): 431-437.

Butterweck, V.; Jurgenliemk, G.; Nahrstedt, A. \& Winterhoff, H. 2000. Flavonoids from Hypericum perforatum show antidepressant activity in the forced swimming test. Planta Medica 66(1): 3-6.

Calixto, J.B. 2000. Efficacy, safety, quality control, marketing and regulatory guidelines for herbal medicines (phototherapeutic agents). Brazilian Journal of Medical and Biological Research 33(2): 179-189.

Constantine, G.H. \& Karchesy, J. 1998. Variations in hypericin concentrations in Hypericum perforatum L. and commercial products. Pharmaceutical Biology 36(5): 365-367.

Crozier, A.; Jensen, E.; Lean, M.E.J.; McDonald, M.S. \& Black, C. 1997. Quantitative analysis of the flavonoid content of commercial tomatoes, onions, lettuce and celery. Journal of Agriculture and Food Chemistry 45(3): 590-595.

Gray, D.E.; Pallardy, S.G.; Garrett, H.E. \& Rottinghaus, G.E. 2003. Effect of acute drought stress and time of harvest on phytochemistry and dry weight of St. John's wort leaves and flowers. Planta Medica 69(11): 1024-1030.

Harborne, J.B. \& Williams, C.A. 2000. Advances in flavonoid research since 1992. Phytochemistry 55(6): 481-504.

Jensen, K.I.N.; Gaul, S.O.; Specht, E.G. \& Doohan, D.J. 1995. Hypericin content of Nova Scotia biotypes of Hypericum perforatum L. Canadian Journal of Plant Science 75(4): 923-926.

Kazlauskas, S. \& Bagdonaitë, E. 2004. Quantitative analysis of active substances in St. John's wort (Hypericum perforatum L.) by the high performance liquid chromatography method. Medicina (Kaunas) 40(10): 975-981.

Kitanov, G.M. 2001. Hypericin and pseudohypericin in some Hypericum species. Biochemical Systematic and Ecology 28(2): 171-178.

Kosuth, J.; Koperdakova, A.T.; Hohtola, A. \& Cellarová, E. 2003. The content of hypericins and phloroglucinols in Hypericum perforatum L. seedlings at early stage of development. Plant Science 165(3): 515-521.

Laakman, G.; Schule, C.; Baghai, T. \& Kieser, M. 1998. St. John's wort in mild to moderate depression: the relevance of hyperforin for the clinical efficacy. Pharmacopsychiatry 31(1): 54-59.

Martins, E.R.; Castro, D.M.; Castellani, D.C. \& Dias, J.E. 1998. Plantas medicinais. Viçosa, Ed. UFV.

Ming, L.C. 1994. Estudo e pesquisa de plantas medicinais na agronomia. Horticultura Brasileira 12(1): 3-9.

Nöldner, M. \& Schötz, K. 2002. Rutin is essential for the antidepressant activity of Hypericum perforatum extracts in the forced swimming test. Planta Medica 68(7): 577-580. 
Pereira, A.M.S.; Câmara, F.L.A.; Caleghini, R.M.S.; Vilegas, J.H.Y.; Lanças, F.M. \& França, S.C. 2000. Variation in coumarin content of Mikania glomerata. Journal of Herbs, Spices \& Medicinal Plants 7(2): 1-10.

Pietta, P.; Garbana, C. \& Pietta, A. 2001. Comparative evaluation of St. John's wort from different Italian regions. Il Farmaco 56(5-7): 491-496.

Santarém, E.R. \& Astarita, L.V. 2003. Multiple shoot formation and hypericin determination in different in vitro tissues of Hypericum perforatum. Brazilian Journal of Plant Physiology 15(1): 43-47.

Schempp, C.M.; Simon-Haarhaus, B. \& Simon, J.C. 2002. Phototoxic and apoptosis-inducing capacity of pseudohypericin. Planta Medica 68(1): 171-173.

Škerget, M.; Kotnik, P.; Hadolin, M.; Hras, A.R.; Simonic, M. \& Knez, Z. 2005. Phenols, proanthocyanidins, flavones and flavonols in some plant materials and their antioxidant activities. Food Chemistry 89(2): 191-198.
Southwell, I.A. \& Bourke, C.A. 2001. Seasonal variation in hypericin content of Hypericum perforatum $\mathrm{L}$. ( $\mathrm{St}$ John's wort). Phytochemistry 56(5): 437-441.

Stefova, M.; Kulevanova, S. \& Stafilov, T. 2001. Assay of flavonols and quantification of quercetin in medicinal plants by HPLC with UV-diode array detection. Journal of Liquid Chromatography and Related Technologies 24(15): 2283-2292.

Thiede, H.M. \& Walper, A. 1994. Inhibition of MAO and COMPT by Hypericum extracts and hypericin. Journal of Geriatric Psychiatry and Neurology 1(1): 54-56.

Vitiello, B. 1999. Hypericum perforatum extracts as potential antidepressants. Journal of Pharmacy and Pharmacology 51(4): 513-517.

Wheatley, D. 1998. Hypericum extract: potential in the treatment of depression. CNS Drugs 9(6): 431-440.

Woelk, H. 2000. Comparison of St. John's wort and imipramine for treating depression: randomised controlled trial. British Medical Journal 321(7260): 536-539. 